2020-08-04

\title{
Characterizing Pain in Long-Term Survivors of Childhood Cancer
}

\author{
Patton, Michaela
}

Patton, M. (2020). Characterizing Pain in Long-Term Survivors of Childhood Cancer (Unpublished master's thesis). University of Calgary, Calgary, AB.

http://hdl.handle.net/1880/112383

Downloaded from PRISM Repository, University of Calgary 


\section{UNIVERSITY OF CALGARY}

Characterizing Pain in Long-Term Survivors of Childhood Cancer

by

Michaela Patton

A THESIS

SUBMITTED TO THE FACULTY OF GRADUATE STUDIES

IN PARTIAL FULFILMENT OF THE REQUIREMENTS FOR THE

DEGREE OF MASTER OF SCIENCE

GRADUATE PROGRAM IN CLINICAL PSYCHOLOGY

CALGARY, ALBERTA

AUGUST, 2020

(C) Michaela Patton 2020 


\begin{abstract}
Many long-term survivors of childhood cancer (LTSCCs) experience late- and long-term effects from their treatments, including pain. Yet, pain is poorly understood among LTSCCs. The current study aims to 1a) identify rates and patterns of chronic pain 1b) describe multiple dimensions of pain, and 2) test predictors of chronic pain in LTSCCs. Survivors [n=140; 48.6\% male, $\mathrm{M}_{\mathrm{age}}=17.3$ years $\left.(\mathrm{SD}=4.9)\right]$ were recruited from across Canada. Participants completed the Pain Questionnaire, Pain Catastrophizing Scale, Pediatric Quality of Life Inventory, Patient Reported Outcome Measurement Information System (PROMIS) - Pain Interference, Anxiety, and Depression scales, Child Posttraumatic Stress Scale, the Posttraumatic Stress Disorder Checklist for the DSM-V, and the Cancer Worry Scale. It was found that $26 \%$ of LTSCCs reported experiencing chronic pain. An exploratory cluster analysis revealed that $20 \%$ of survivors had a moderate to severe chronic pain problem based on measures of pain intensity and interference. The combination of anxiety, depression, PTSS, cancer worry, current age, age at diagnosis, pain catastrophizing, and sex significantly predicted the presence of chronic pain, $\chi^{2}(8$, $N=123)=27.87, p<.001$. Higher pain catastrophizing $(\mathrm{OR}=1.09 ; 95 \% \mathrm{CI}=1.03-1.15)$ and older current age $(\mathrm{OR}=1.13 ; 95 \% \mathrm{CI}=1.01-1.27)$ were significant predictors of chronic pain. LTSCCs should be screened for the presence and magnitude of chronic pain during their longterm follow-up visits so appropriate interventions can be discussed. Future research should investigate pain interventions tailored for this population.
\end{abstract}

KEYWORDS: Childhood Cancer, Survivorship, Pain, Chronic Pain, Psychosocial 


\section{Preface}

This thesis is original, unpublished, independent work by the author, Michaela Patton. The research described here within was approved by the Health Research Ethics Board at the University of Calgary, certificate number HREBA.CC-17-0059_REN3 for the project "WellBeing and Pain in Survivors of Childhood Cancer" on June 2, 2017. 


\section{Acknowledgements}

I would like to thank the following people, without whom I would not have been able to complete this research, and without whom I would not have made it through a master's degree in Clinical Psychology.

My incredible supervisor, Dr. Fiona Schulte, for your uwavering support and encouragement as well as the endless opportunities you provide me.

My lab members who helped with the larger study this thesis is a part of including Caitlin Forbes, Courtney Charnock, Elleine Allapitan, and Mehak Stokoe. A special thank you to Brooke Russell for being a constant support to me throughout my time in this program. Thank you to my committee members, Dr. Melanie Noel and Dr. Linda Carlson for your insightful input and constructive feedback. I am lucky to work with two brilliant women in science such as yourselves!

My patient partners Dr. Victoria Forster and Madison Tutt for helping me with this project every step of the way. I am grateful for your time and efforts in making this project beneficial for other survivors of childhood cancer.

All the survivors who participated in this study. I could not have done this without your dedication to science.

Finally, I extend my most heartfelt appreciation to my family and friends who have helped and supported me throughout this journey in graduate school. 
Table of Contents

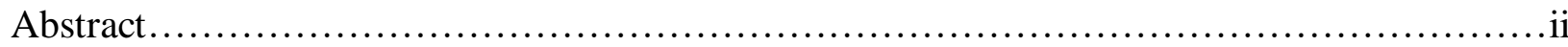

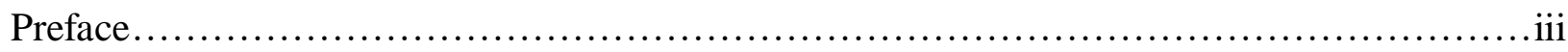

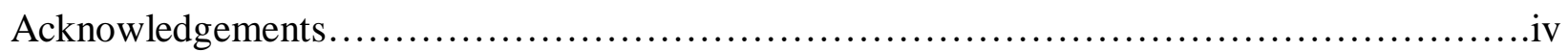

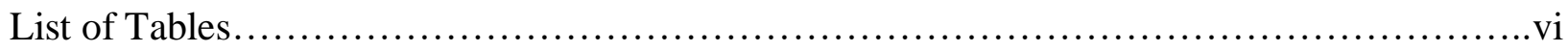

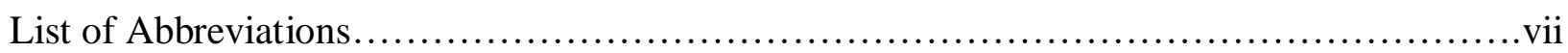

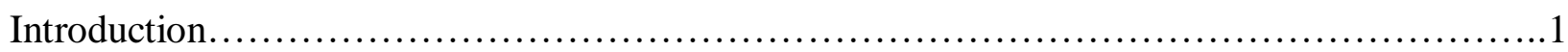

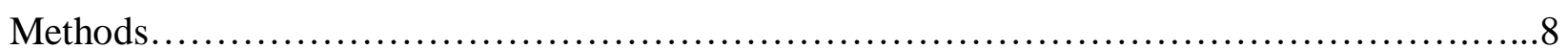

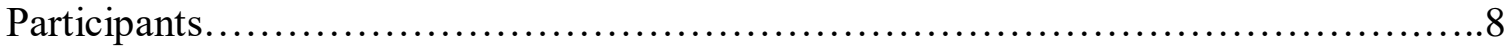

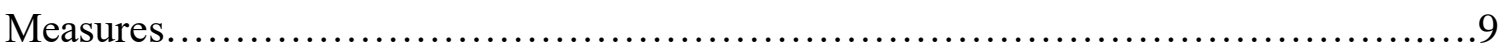

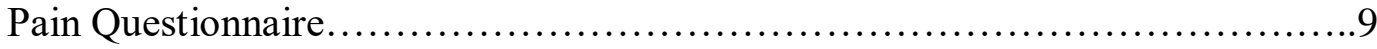

PedsQL............................................................. 10

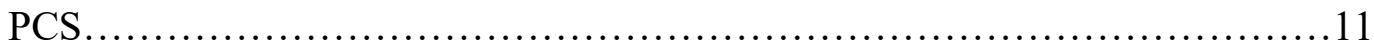

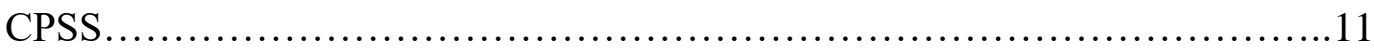

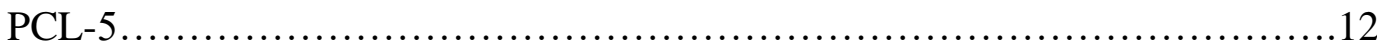

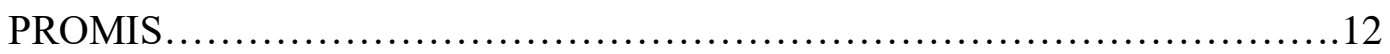

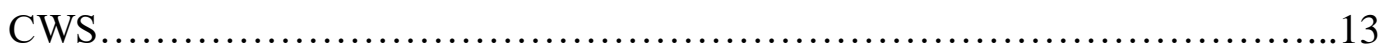

ITR-3 .......................................................... 13

Demographic Information......................................... 14

Procedure................................................................... 14

Statistical Analyses..................................................... 14

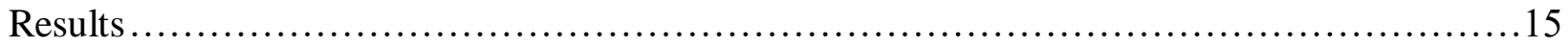

Demographic Information.................................................. 15

Rates of and Patterns of Chronic Pain............................................. 16

Multiple Dimensions of Pain................................................. 16

Predictors of Chronic Pain....................................................... 17

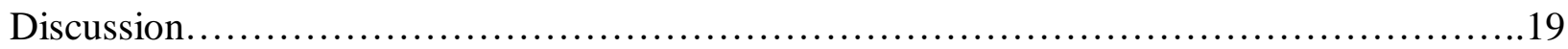

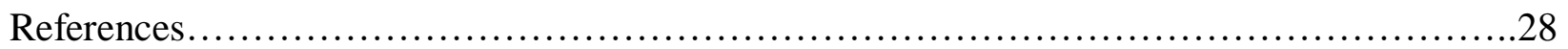

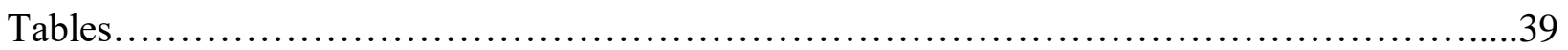

Table 1. Demographic Characteristics........................................ 39

Table 2. Demographic Characteristics of Survivors $<18$ Years Old...................40

Table 3. Pain Outcomes........................................................41

Table 4. Chronic Pain, Pain Intensity, and Pain Interference Cluster Analysis.............42

Table 5. Differences in Psychosocial, Treatment, and Diagnosis Variables in Survivors with versus without Chronic Pain ............................................43

Table 6. Correlations between Predictor Variables..................................44

Table 7. Predictors of Chronic Pain...........................................45 
List of Tables

Table 1. Demographic Characteristics and Treatment Variables

Table 2. Demographic Characteristics of Survivors < 18 Years Old

Table 3. Pain Outcomes

Table 4. Chronic Pain, Pain Intensity, and Pain Interference Cluster Analysis

Table 5. Differences in Psychosocial, Treatment, and Diagnosis Variables in Survivors with versus without Chronic Pain

Table 6. Correlations between Predictor Variables

Table 7. Predictors of Chronic Pain 
List of Abbreviations
ALL acute lymphoblastic leukemia
CPSS Child Posttraumatic Stress Scale
CWS Cancer Worry Scale
HRQL health-related quality of life
LTSCCs long-term survivors of childhood cancer
PCL-5 Posttraumatic Stress Disorder Checklist for the DSM-5
PCS Pain Catastrophizing Scale
PedsQL Pediatric Quality of Life Inventory
PROMIS Patient Reported Outcome Measurement Information System
PQ Pain Questionnaire
PTSS Posttraumatic Stress Symptoms
ITR-3 Intensity of Treatment Rating Scale - Version 3 


\section{Introduction}

Due to medical advances in cancer treatment and improved early screening strategies, more individuals are surviving pediatric cancer (i.e., cancer diagnosed $<21$ years of age) than ever before. There are currently over 30,000 survivors of childhood cancer living in Canada alone and this number is projected to continue growing exponentially (Siegel, Miller, \& Jemal, 2016). Survival rates in developed countries have increased from 58 to $83 \%$ in the last several decades, making survivors of childhood cancer a rapidly growing population. While it is encouraging that children diagnosed with cancer currently have a much greater chance at survival than they did several decades ago, achieving cure requires toxic and aggressive treatments that can consequently cause an array of side effects. It has been found that approximately two-thirds of long-term survivors of childhood cancer (LTSCCs) will experience late- and long-term effects from their cancer and its treatments (Blaauwbroek, Groenier, Kamps, Meyboom-de Jong, \& Postma, 2007; Twycross, Parker, Williams, \& Gibson, 2015). These lateeffects can be biological, psychological, or social in nature, and can lead to increased disability and diminished quality of life. As a result, research is urgently needed to better understand how to minimize potential biopsychosocial consequences of cancer and support the health and wellbeing of children during treatment and into survivorship.

Chronic pain is an example of a potential late effect of cancer treatment. During treatment, pain can originate from procedures like lumbar punctures, surgery, bone marrow aspirations, and venipunctures. While these procedures are in the realm of acute pain, poorly managed procedural and postoperative pain has the potential to become a long-lasting problem. A recent systematic review and meta-analysis found that chronic post-surgical pain is estimated to affect $20 \%$ of children undergoing major surgeries (Rabbitts, Fisher, Rosenbloom, \& Palermo, 
2017). Pain can also arise from certain cancer treatments such as radiation to the bone or joint and certain types of chemotherapy like vincristine, or from the cancer itself such as tumors impeding on bone or tissue (Bennett et al., 2019; Cummings, Reid, Finley, McGrath, \& Ritchie, 1996), but little is known about the long-lasting effects and if this pain resolves over time. Pain can stem from other underlying conditions unrelated to the cancer or its treatment such as preexisting musculoskeletal or neuropathic pain syndromes that could potentially be exacerbated by aggressive cancer treatments. Finally, pain can emerge as a result of late effects of treatment (e.g., osteonecrosis). Considering all the various sources of pain that children diagnosed with cancer may endure during and after their treatment, it is imperative that efforts are made to better understand the pain experience of survivors of childhood cancer in order to best promote their health and well-being.

Little is known about the prevalence or pathology of chronic pain in survivors of childhood cancer. However, the prevalence of chronic pain in survivors of adult cancer has been reported to be as high as $40 \%$ (van den Beuken-van Everdingen, Hochstenbach, Joosten, TjanHeijnen, \& Janssen, 2016). Accordingly, the International Association for the Study of Pain recently assembled a task force to create a new classification of chronic pain in the International Classification of Diseases (ICD-11) called chronic cancer-related pain (Bennett et al., 2019). Acknowledging the vast number of origins that pain can stem from in this unique population, this task force identified two codes subclassifying chronic cancer-related pain into chronic cancer pain and chronic postcancer treatment pain. Under chronic cancer pain, codes were created to represent the pain experiences during cancer treatment such as chronic visceral cancer pain or chronic neuropathic cancer pain. Under chronic postcancer treatment pain, codes were created to represent pain experiences after cancer treatment has concluded such as chronic post-cancer 
medicine pain or chronic painful radiation-induced neuropathy. This new classification for chronic cancer-related pain serves as an important milestone in addressing the unique biopsychosocial histories of survivors of cancer and provides guidance into future research characterizing pain in this population.

Predictors of chronic pain in adult cancer survivors include the type and invasiveness of a tumor, amputation, limb-sparing surgery, vincristine, the patient's treatment regimen, osteonecrosis, time since cancer treatment, and the effectiveness of initial pain management strategies (Mertens et al., 2008). Chronic pain in this population has also been shown to be related to diminished quality of life (Green, Hart-Johnson, \& Loeffler, 2011). Thus, chronic pain has been identified as a prevalent and impairing issue in adult cancer survivors.

Pain can arise from a myriad of biopsychosocial origins in cancer survivors, yet there still exists a scarcity of research on the topic. It is also important to study pediatric cancer survivors separately from adult cancer survivors for several reasons. First, some children are too young to remember their experiences leading up to diagnosis and throughout cancer treatment. Based on growing evidence in the role of youth's memories of painful experiences in how they experience pain in the future (Noel, Rabbitts, Fales, Chorney, \& Palermo, 2017), survivorship may be a completely different experience for those who have little or no recollection of their time from diagnosis to treatment completion. Second, younger populations are important to focus on because they receive toxic treatments on their developing bodies, where adults with cancer undergo treatment on their full-grown bodies. It is possible that growth and developmental factors related to pain could be different between these two groups in survivorship. Third, children are diagnosed with different cancers than adults. The most commonly diagnosed cancers among children are leukemias and central nervous system tumors, whereas the most commonly 
diagnosed cancers among adults are breast and lung cancer (American Cancer Society, 2019). Thus, children receive different treatment regimens than adults because they are treated for different diseases.

While research in chronic pain in adult cancer survivors is slowly gaining momentum, chronic pain in pediatric cancer survivors is less understood. Data gathered from the long-term survivors clinic at Alberta Children's Hospital in Calgary, Alberta using a health questionnaire, revealed that $52 \%$ of survivors at least 10 years off treatment reported pain at one of their regular visits while $24.9 \%$ reported pain at multiple visits (Patton et al., In Preparation), suggesting that a subset of these survivors could potentially be experiencing chronic pain. Nevertheless, pain was not assessed using psychometrically sound and theoretically-grounded measures because the primary purpose of these health questionnaires is to maximize clinical utility and facilitate conversations between survivors and their physician during follow-up visits. More research is needed to better understand whether current strategies for screening and assessing pain are effective enough to provide survivors access to necessary pain management.

A topical review reported a prevalence of chronic pain in LTSCCs ranging anywhere from 5-59\% (Alberts, Gagnon, \& Stinson, 2018). A recent systematic review of pain in LTSCCs found that pain outcomes are typically analyzed based on a single item or small subset of items derived from health-related quality of life questionnaires, symptom inventories, and items created by the authors for the purpose of the study (Schulte et al., In Preparation). These methods for assessing pain greatly impede multidimensional understanding of pain location, duration, frequency, intensity, interference, and affect, which cannot all be assessed using one or two items. This systematic review revealed that the presence of pain in pediatric cancer survivors reported in the literature currently ranges anywhere from $4.3-75 \%$. Additionally, it was found 
that less than $17 \%$ of these studies incorporated pain in their primary objectives, which suggests that pain may not necessarily be a focal point in research on LTSCCs and may explain why studies do not utilize sound measures of pain.

Only three studies to date (Bowers et al., 2012; Johannsdottir et al., 2017; Sadighi et al., 2014) have investigated chronic pain by its definition, which is pain lasting more than 3 months (Treede et al., 2015). Two studies focused on survivors of childhood acute lymphoblastic leukemia (ALL). One study investigating back pain in surivors of ALL (Bowers et al., 2012) found that $44 \%$ of ALL survivors $(n=99)$ reported chronic back pain compared to $21 \%$ of their siblings. The second study investigating headaches in ALL survivors (Sadighi et al., 2014) found that $11 \%$ of their sample $(n=72)$ reported chronic daily headaches. The third study found that $56 \%$ of lymphoma survivors reported having any type of chronic pain (Johannsdottir et al., 2017). In sum, understanding of chronic pain in survivors of pediatric cancer is limited to headaches and backpain in ALL survivors and general chronic pain in lymphoma survivors. No studies to date have examined chronic pain in any other diagnoses.

Not only is pain a multidimensional construct, it is also a complex, biopsychosocial experience. In line with the biopsychosocial model, pain is affected by and can affect a wide range of biological, psychological, and social aspects of a person's well-being (Engel, 1977). Although studies examining pain among survivors of childhood cancer have not utilized theoretically-grounded, multidimensional measures of pain, most studies still reported on biopsychosocial factors related to pain. While these findings should be interpreted with caution based on the way pain is measured, results from these studies can, indeed, inform future research and highlight potential mechanisms contributing to and factors affected by pain in general. Across studies, females consistently reported more pain than males (Alessi et al., 2007; Arpaci \& 
Kilicarslan Toruner, 2016; Bowers et al., 2012; Hudson et al., 2003; Lu et al., 2011; Marina et al., 2013; Pogany et al., 2006; Recklitis et al., 2019; Sadighi et al., 2014). Pain was also related to younger age at diagnosis (Cox et al., 2009; Lu et al., 2011; van Dijk et al., 2008), and impaired health-related quality of life (Finnegan et al., 2009; Macartney, VanDenKerkhof, Harrison, \& Stacey, 2014; Recklitis et al., 2019; Schultz et al., 2014). Additionally, pain has been found to be associated with psychological distress (Brinkman et al., 2013; D'Agostino et al., 2016; Oancea et al., 2014), depression (Brinkman et al., 2013; Meeske, Siegel, Globe, Mack, \& Bernstein, 2005; Oancea et al., 2014), and anxiety (Cox et al., 2009; Oancea et al., 2014). Social factors related to pain identified in the literature have been lower socioeconomic status (Crom et al., 2010; Hudson et al., 2003; Oancea et al., 2014) and lower educational level. Finally, Hispanic and African American survivors have shown to be more likely than Caucasian survivors to report pain (Lu et al., 2011) but further research is needed to understand why these differences exist.

Research on pain in LTSCCs can be informed by the pediatric chronic non-cancer pain literature to explore the prevalence and magnitude of chronic pain as well as variables that may be related to chronic pain in cancer survivors. Epidemiological studies on youth in the general population have demonstrated that chronic pain is a prevalent issue (Huguet \& Miro, 2008; King et al., 2011). Of even more importance, it was identified that 5-8\% of youth have moderate to severe chronic pain problems when taking into account pain severity and interference among youth who report having chronic pain (Huguet \& Miro, 2008). A five-class system was proposed to help characterize the magnitude of the chronic pain problem, using certain cuttoff scores to operationally define mild, moderate, and severe pain intensity and interference among youth with chronic pain. In terms of factors related to chronic pain, post-traumatic stress symptoms (PTSS) have been a focal point in the chronic non-cancer pain literature, and one study found 
significantly higher PTSS in adolescents with chronic pain compared to healthy controls (Noel, Wilson, et al., 2016). A population-based longitudinal study revealed that adolescents who reported experiencing chronic pain were more likely to develop anxiety and depressive disorders in adulthood (Noel, Groenewald, Beals-Erickson, Gebert, \& Palermo, 2016).

There are a number of theoretical models that can help organize research around pain in LTSCCs. The fear avoidance model of pain suggests that the mysteries behind the development of chronic pain and disability can be partially explained by an individual's pain-related fears and avoidance of activity over and above the severity of their pain. This model takes into account how anxiety, hypervigilance to bodily sensations, and pain catastrophizing can put individuals at risk for developing disabling chronic pain. On the other hand, this model suggests that low fear of pain leads to confrontation of pain, which then leads to recovery. Additionally, there have been theoretical models of fear of cancer recurrence that suggest those with a history of cancer have a unique relationship to pain as it relates to their cancer history and the potential for relapse (Heathcote \& Eccleston, 2017). This particular model proposes that based on the individual's cancer history, their interpretation of pain as being related to a cancer relapse can drive a cycle of fear, worry, and hypervigilance to bodily sensations. Consistent with the mutual maintenance model of pain and anxiety, increased anxiety and hypervigilance could, in turn, worsen the experience of pain (Asmundson \& Katz, 2009). These models have yet to be tested in LTSCCs. Using frameworks from the chronic non-cancer pain literature will help guide research that can lead to better assessment of pain and the development of tailored pain interventions for LTSCCs. A topical review on chronic pain in LTSCCs proposed a theoretical framework to be used in future research that includes many potential interacting factors that could drive and be affected by chronic pain in this population (Alberts et al., 2018). This model shows that the cancer 
diagnosis can be broken up into disease, treatment, and procedural factors that can put survivors at greater risk of developing chronic pain. Furthermore, there are likely bi-directional relationships between emotional distress, lifestyle factors, and medical late effects and the presence of chronic pain. Finally, the model specifies that there are underlying developmental factors that affect the way that pain presents, which interacts with all factors related to pain. Given the comorbidities associated with chronic pain and the vulnerability among survivors of childhood cancer, it is critical that we aim to develop a better understanding of pain in this LTSCCs.

Thus, the aims of the current study were to: 1a) identify rates and patterns of chronic pain; 1b) describe multiple dimensions of pain in survivors of childhood cancer; and 2) test predictors of chronic pain. It is hypothesized that: 1) a subset of survivors will endorse 'yes' to experiencing pain for at least three months on the Pain Questionnaire (PQ); 2) significantly different classes of survivors will arise based on reports of chronic pain, pain intensity and pain interference as observed in the chronic non-cancer pain literature; 3) survivors will show variability in their reports of pain intensity, interference, frequency, duration, location, and distress; and 4) psychosocial (anxiety, depression, PTSS, HRQL, and pain catastrophizing), biological (sex, current age), and clinical (age at diagnosis, treatment intensity, type of diagnosis, age at diagnosis) variables will be related to chronic pain.

\section{Methods}

\section{Participants}

Ethics approval for this study was obtained via the local institutional review board (HREBA.CC-17-0059). Participant inclusion criteria was: survivors of childhood cancer of a variety of diagnoses from across Canada; current age 8-25 years; diagnosed < 21 years of age; at 
least 2 years post-treatment or 5 years post-diagnosis. Exclusion criteria was: acute medical issues including major injury, illness, or surgery within the past year, diagnosed psychosis or developmental disability such as autism spectrum disorder or intellectual disability, are unable to speak and read English fluently, or do not currently live in Canada. Eligible participants were recruited from the Hematology, Oncology, and Transplant Program at Alberta Children's Hospital during their regular long-term survivor follow-up care visit. Additionally, eligible participants were recruited from social media and other online modalities.

\section{Patient Engagement}

Two patient partners were recruited via conference networking at a scientific meeting that invited individuals with lived experiences to take part. Our patient partners were included in decision-making during various phases of the current study. One patient partner was a 25-year survivor of ALL and one patient partner was a five-year survivor of neuroblastoma. Our patient partners were consulted regarding the design, selection of measures, recruitment of participants, and interpretation of results. As a result of their input, we included more comprehensive items in the demographic questionnaire about cancer and treatment history. Additionally, our patient partners were integral in recruiting participants from social media as well as from within their patient advocacy groups. Finally, our patient partners played a vital role in the interpretation of findings, which shaped the discussion of results.

\section{Power Analysis}

A power analysis was conducted to determine our ability to detect differences between groups with a proposed sample of 158 . Using $\mathrm{G}^{*}$ Power 3.1 , with 158 participants in two groups for a one-way ANCOVA, a conservative estimated effect size of cohen's $f=0.35$ and a significance level $p<.05$, would achieve a power of 0.85 . Based on previous research, this effect 
size was considered sufficient to detect significant differences between groups (Fales, Murphy, Rights, \& Palermo, 2019). Using the obtained sample size of 140, the analysis achieved a power of 0.79 which is considered acceptable. A power analysis was conducted using G*Power 3.1 for a logistic regression analysis (chronic pain vs. no pain) to determine our ability to explore variables related to the experience of chronic pain. Based on previous research (Patton et al., In Preparation), we used an estimated $R^{2}$ of 0.4 and a projected odds ratio of 1.8 and a significance level $p<.05$, a sample of 140 is required to obtain power of 0.80 .

\section{Measures}

\section{Primary Outcome:}

Pain Questionnaire (McGrath, 1990). The Pain Questionnaire is a 7-item self-report measure of pain, which assesses pain frequency, location, duration, intensity, and emotional upset due to pain. Pain frequency was assessed with an item asking, "In the past 7 days, how often have you had aches or pains?" in which the response options were "Not at all," "1 time per week," "2 to 3 times per week," "4 to 6 times per week," and "Daily." Of note, survivors who answered "not at all" to this item were not provided subsequent items about pain. Pain location was assessed with an item asking, "In which part of your body did you experience the most aches or pains?" in which the response options were "Stomach," "Head," "Muscles and joints," “Legs," "Chest," and "Other (Please Specify)." Pain duration was assessed with an item asking, "How long do your aches or pains usually last?" in which the response options were "Less than 1 hour," "A few hours," "Half of the day," and "All day." Pain intensity was assessed with an item asking about the magnitude of pain experienced, "When you have aches or pain, how much hurt do you usually have?" answered on a 0-10 Likert scale. This measure of pain intensity has demonstrated to be a reliable and valid measure of pain in many populations of children 8 years 
and older (Castarlenas, Jensen, von Baeyer, \& Miro, 2017; von Baeyer et al., 2009). Emotional distress due to pain was assessed with the item, "How much do aches or pains bother or upset you?", in which the response options were "Not at all," "A little," "Between a little and a lot," "A lot," and "Very much." To assess for the presence of chronic pain, participants were asked, "Have you had pain for at least 3 months in a row?" in which they could respond "Yes" or "No." If participants responded "Yes," they were asked "How long have you had this pain?" in which they responded with the number of years, months, and days they have had that pain. The PQ has not yet been validated in populations with cancer.

\section{Secondary Outcomes:}

Pediatric Quality of Life (PedsQL) - Generic Core (Varni, Seid, \& Kurtin, 2001). The PedsQL - Generic Core module is a 23-item self-report measure of health-related quality of life (HRQL) which assesses physical, social, emotional, and cognitive domains. Subscores were summed to provide a total score from 0-100. Higher scores reflect better overall HRQL. This tool has been used frequently and is well validated within pediatric oncology populations for ages 8-25 years (Varni, 1996; Varni et al., 2001). Internal consistency for the child $(n=33)$, adolescent $(n=44)$, and young adult $(n=62)$ measures were $.860, .913$, and .925 , respectively.

Pain Catastrophizing Scale - Child Self-Report (PCS-C) (Crombez et al., 2003). The

PCS-C is a 13-item measure used to assess catastrophic thoughts and feelings around pain. Participants rated statements about their pain on a five-point Likert scale (i.e.: "when I have pain I can't keep it out of my mind"). Items were summed to yield a total score where higher scores indicate more catastrophizing. The PCS-C has been found to have good validity and reliability in youth with pain. The PCS-C has not been validated in oncology populations. The PCS has been used in breast cancer survivors (Lee et al., 2017) and patients with lung cancer (Prasertsri, 
Holden, Keefe, \& Wilkie, 2011), but the PCS-C has not yet been used in oncology. Internal consistency for our sample was .917.

\section{Child Posttraumatic Stress Scale (CPSS-V) (Foa, Johnson, Feeny, \& Treadwell,}

2001). The CPSS is a 17-item self-report measure for children used to assess posttraumatic stress symptoms regarding re-experiencing, avoidance, and arousal. The original CPSS was created to reflect the DSM-IV-TR (American Psychiatric Association, 2000) criteria for post-traumatic stress disorder (PTSD), but was recently updated to reflect the DSM-V criteria for PTSD (American Psychiatric Association, 2013). Items are rated on a four-point Likert scale from 0 "Not at all" to 3 "Five or more times a week". This tool has been found to have excellent internal consistency and good convergent validity, concurrent validity, and discriminant validity in school-based adolescents (Stewart, Ebesutani, Drescher, \& Young, 2017). It has also demonstrated excellent internal consistency and good test-retest reliability, convergent and discriminant validity among a sample of treatment-seeking children with trauma histories (Nixon et al., 2013). While the original authors proposed a three-factor model, confirmatory factor analysis supported the use of a one-factor model using a total symptom score. Of interest to the current study, one study found significantly higher scores on the CPSS in children with chronic non-cancer pain compared to those without chronic pain (Noel, Wilson, et al., 2016). This measure has shown to be reliable and valid for children 8 years and older, but has not yet been validated in pediatric cancer populations. The CPSS was completed by survivors age 8-17 years. Internal consistency for our sample was .946.

\section{Posttraumatic Stress Disorder Checklist for DSM-5 (PCL-5) (Blevins, Weathers,}

Davis, Witte, \& Domino, 2015). The PCL-5 is a 20-item self-report measure that assesses PTSD symptoms experienced over the past month, and was created in line with the DSM-V criteria for 
PTSD (American Psychiatric Association, 2013). Each item is rated on a five-point Likert scale from 0 "Not at all" to 4 "Extremely" and are summed together to create a continuous measure of PTSD symptoms. This tool has been found to have excellent internal consistency, good testretest reliability, and good convergent and discriminant validity in trauma-exposed college students (Blevins et al., 2015) as well as a general population of undergraduates (Ashbaugh, Houle-Johnson, Herbert, El-Hage, \& Brunet, 2016). However, this tool has not yet been validated in individuals with histories of cancer. This measure was completed by survivors age 18-25 years. Internal consistency for our sample was .929.

\section{Patient Reported Outcomes Measurement Information System (PROMIS) (Cella et}

al., 2010). The PROMIS Anxiety and Depression instruments (8-item short form) were administered to screen for current symptoms of anxiety and depression. Survivors completed the self-report instrument corresponding to their age (child: age 8-17; adult: age 18+). Items (e.g., "I felt worried") are rated on a five-point scale from 1 "Never" to 5 "Always". Higher scores signify greater severity of symptoms. Pain interference was assessed using the four item PROMIS interference scale for survivors 8-17 years of age, and the eight item PROMIS interference scale for survivors over 18 years of age (Hinds et al., 2013). The PROMIS pediatric measures have been validated for use in pediatric oncology (Hinds et al., 2013). Internal consistency for child $(n=69)$ and young adult $(n=70)$ measures of anxiety were .932 and .956 , respectively. Internal consistency for child $(n=69)$ and young adult $(n=70)$ measures of depression were .969 and .948 , respectively. Internal consistency for child $(n=69)$ and young adult $(n=69)$ measures of pain interference were .898 and .966 , respectively.

Cancer Worry Scale (CWS) (Custers et al., 2014). The CWS is an eight-item questionnaire that asked survivors about their specific worries around relapse and developing a 
secondary malignancy. Items (e.g., "How often have you thought about your chances of getting cancer (again)?”) are rated on a four-point scale from "Never" to "Almost always". Higher scores indicate greater severity of cancer worry. The CWS has been validated in adult breast cancer survivors (Custers et al., 2014), adult colorectal cancer survivors (Custers, Gielissen, Janssen, de Wilt, \& Prins, 2016), adult prostate cancer survivors (van de Wal et al., 2016), and patients with gastrointenstinal stromal tumors (Custers et al., 2015). The instrument has also been used in childhood cancer survivors (Klassen et al., 2015) as well as adolescent and young adult cancer survivors (Thewes, Lebel, Seguin Leclair, \& Butow, 2016), but has not yet been validated in individuals under the age of 15 years. Internal consistency for our sample was .906.

Intensity of Treatment Rating Scale Version 3 (ITR-3) (Kazak et al., 2012). The ITR3 is a method for classifying the intensity of pediatric cancer treatments. It classifies treatments into four intensity levels based on diagnosis, stage, and treatment data obtained from medical records. Interrater reliability was shown to be high in previous validation studies between 47 oncologists, with a median agreement of 0.90 and an intraclass correlation coefficient of $r_{\text {ICC }}=$ 0.86. Agreement between two raters in $20 \%$ of the sample in the current study was shown to be 0.82. All discrepencies were resolved through consensus.

Demographics. Demographic information from survivors was collected including current age and ethnicity. Additional demographic information was collected from parents of survivors under 18 years old including household income, mother's education, and father's education. Information was collected from survivors about their cancer history including diagnoses, treatments, and relapse. Finally, medical information from patient charts was collected including: sex, diagnosis date and description, and treatment received.

\section{Procedure}


Eligible participants were approached during their regular Long-Term Survivor Clinic visits to assess their interest in participating. If warranted, details of the study were provided by a member of the research team. Additionally, the study advertised on social media and other online modalities to recruit survivors across Canada. Upon agreement to participate, survivors or parents were contacted via phone to undergo screening by a member of the research team. If eligible, participants were emailed unique links to complete the questionnaire package online via Research Electronic Data Capture (REDCap). Survivors were given access to the questionnaire only upon completion of the appropriate electronic consent forms, located at the beginning of the questionnaire. For survivors under the age of 18 years, caregivers provided consent for their children's participation. Survivors under the age of 18 years also provided assent. Survivors over the age of 18 years provided their own consent.

\section{Statistical Analyses}

All statistical analyses were performed using SPSS 25. To address aim 1a, frequencies were used to report the number of survivors in the sample who endorsed "Yes" to experiencing pain at least three months on the Pain Questionnaire (PQ). Additionally, an exploratory cluster analysis was used to identify classes of chronic pain problems based on the presence of chronic pain and scores of pain intensity and interference. To address aim $1 \mathrm{~b}$, descriptive statistics and frequencies were used to describe pain intensity, interference, frequency, duration, location, and distress. To address aim 2, we first explored the psychological (i.e., anxiety, depression, PTSS, cancer worry, pain catastrophizing, and quality of life), biological (i.e., sex, current age), and clinical (age at diagnosis, treatment intensity, type of diagnosis, age at diagnosis) variables that bore the greatest statisistical relationship to chronic pain via one-way Analyses of Variance $($ ANOVA) $(\mathrm{p}<.05)$ and bivariate correlation analyses $(\mathrm{r}>0.2, \mathrm{r}<0.7)$. We also aimed to ensure 
the assumption of multicollinearity was not violated for subsequent analyses $(r>0.7)$.

Subsequently, we conducted a logistic regression analysis to determine which variables predicted chronic pain among survivors of childhood cancer.

\section{Results}

\section{Demographic Information}

Participant demographics representing the whole sample are outlined in Table 1. Because information was not collected about whether survivors reside with their parents or not, parent socioeconomic variables for survivors under the age of 18 years are outlined separately in Table 2 , with the assumption that survivors under 18 years of age live with their parents. Of the 254 eligible survivors invited to participate, 176 agreed to participate, and 78 declined. Reasons for declining included, "Not interested" $(n=9)$, "Not able to participate at this time" $(n=5)$, "Reflecting on cancer experience is too traumatic" $(n=1)$, or no reason provided $(n=63)$. Of the 176 who agreed to participate, 140 completed the study. Survivors were on average 17.3 (SD = 4.9) years old at the time of the study and ranged from eight to 25 years old. The sample included $67(47.9 \%)$ survivors under the age of 18 years and $73(52.1 \%)$ survivors 18 years or older. The sex of participants were 72 (51.4\%) females, and 68 (48.6\%) males. With regards to ethnicity, 96 (78.0\%) survivors identified as Caucasian, 11 (8.9\%) other/mixed ethnicity, four (3.3\%) Arab, three (2.4\%) Southeast Asian, two (1.6\%) Latin American, two (1.6\%) South Asian, two (1.6\%) East Asian, two (1.6\%) First Nations/Métis/Inuit, and one (0.8\%) AfricanCanadian. Average time off treatment was approximately 9.9 years and average age at diagnosis was approximately 6.3 years. Thirteen (9.3\%) survivors were recruited online who were not currently being followed by the Long-Term Survivor Clinic at the Alberta Children's Hospital.

\section{Aim 1a: Rates and patterns of chronic pain}


It was found that $36(26.1 \%)$ survivors reported having chronic pain according to its definition of pain lasting three months or longer (Treede et al., 2015). Survivors who reported "Yes" to this item were asked how long their pain has persisted, which ranged from six months to 11 years. Survivors who reported 'yes' to experiencing chronic pain $(n=36)$ were subsequently asked to rate their pain interference and pain intensity. These values were converted to $z$-scores and were analyzed by the $k$-means cluster procedure. Convergence was reached in seven iterations for three unique classes. Univariate ANOVAs indicated that the cluster groups differed significantly on both variables (both $p \mathrm{~s}<.001$ ). The final cluster centers together with the number of cases in each cluster are shown in Table 4 . The range in $n$ for each cluster was six to 17 . Cases in Cluster $1(n=11)$ appeared to have high levels of pain interference and high levels of pain intensity. Cases in Cluster $2(n=6)$ appeared to have low levels of pain interference and low levels of pain intensity. Cases in Cluster $3(n=17)$ appeared to have moderate-to-high levels of pain interference and moderate levels of pain intensity.

\section{Aim 1b: Multiple dimensions of pain}

Descriptive statistics were used to describe multiple dimensions of pain across the whole sample of survivors of childhood cancer, which can be found in Table 3. On a scale of zero (not at all) to four (daily), survivors reported a mean pain frequency of 1.08 ( $\mathrm{SD}=1.34)$. Survivors who reported pain at least once in the past week reported a mean pain intensity of $4.33(\mathrm{SD}=$ 1.95) on a scale of zero (no pain) to 10 (worst possible pain). Among those who reported having pain in the past week, $32(46.4 \%)$ reported pain in their muscles and joints, $14(20.3 \%)$ reported pain in their legs, 10 (14.5\%) reported pain in 'other' locations (i.e., back, neck, ear), nine (13.0) reported pain in their head, and four (5.8\%) survivors reported pain in their stomach. No survivors reported pain in their chest. Among survivors with chronic pain, the most common 
pain location was in the mucles and joints (50.0\%), 'other' (20.6\%), and legs (17.6\%). Survivors reported a mean pain duration of $1.26(\mathrm{SD}=1.16)$ on a scale of zero (less than one hour) to three (all day). Finally, survivors reported a mean pain distress rating of $1.48(0.85)$ on a scale of zero (not at all) to four (very much).

\section{Aim 2: Predictors of chronic pain}

Biological, clinical and psychosocial variables for the chronic pain vs. no chronic pain groups can be found in Table 5. Bonferroni correction was used to correct for multiple comparisons and reduce the chance for committing a Type I Error. $\chi^{2}$ analyses and one-way ANOVAs revealed that survivors with chronic pain did not differ from survivors without chronic pain by $\operatorname{sex}\left[\chi^{2}(1)=2.85, \mathrm{p}=.120\right]$, time off treatment $[F(1,130)=0.03, p=.871]$, or treatment intensity $[F(1,120)=0.53, p=.467]$. Survivors with chronic pain $(\mathrm{M}=18.63, \mathrm{SD}=4.87)$ were significantly older at the time of the study than survivors without chronic pain $(M=16.79, \mathrm{SD}=$ $4.87),[F(1,136)=3.90, p=.050]$, and survivors with chronic pain $(\mathrm{M}=7.96, \mathrm{SD}=5.62)$ were significantly older at diagnosis than survivors without chronic pain $(\mathrm{M}=5.74, \mathrm{SD}=4.54),[F(1$, $121)=4.99, p=.027]$. Compared to survivors without chronic pain, survivors with chronic pain reported significantly higher anxiety $[F(1,135)=12.89, p<.001]$, posttraumatic stress symptoms $[F(1,135)=10.98, p=.001]$, and significantly worse health-related quality of life $[F(1,135)=$ 65.28, $p<.001]$. With the more stringent alpha level, there were no significant group differences in depression $[F(1,135)=6.21, p=.014]$ or cancer worry $[F(1,135)=6.71, p=.011]$.

Bivariate correlation analyses were conducted to examine relationships among variables and to ensure the assumption of multicollinearity was not violated for subsequent analyses. Results of these analyses can be found in Table 6. A standard binary logistic regression was used to identify relationships between potential biological, clinical, and psychosocial variables and the 
presence of chronic pain (using the presence of chronic pain as the target category). Predictor variables selected for the model were based on those bearing the greatest statistical relationship to chronic pain $(r>0.2, r<0.7)$, or those for which there existed a strong theoretical rationale. Therefore, the predictor variables selected for the regression model were the binary variable sex and the quantitative variables of current age, anxiety, depression, pain catastrophizing, PTSS, cancer worry, and age at diagnosis. Based on a classification threshold predicted probability of target group membership as 0.50 , results of the logistic regression analysis indicated that the eight-predictor model provided a statistically significant prediction of the presence of chronic pain, $\chi^{2}(8, N=123)=27.87, p<.001$. The Nagelkerke pseudo $R^{2}$ indicated that the model accounted for approximately $30 \%$ of the total variance. Classification accuracy for the cases based on a classification cutoff value of 0.50 for predicting membership in the chronic pain group was moderately high, with an overall correct prediction rate of $77.2 \%$ and correct prediction rates of $37.5 \%$ for the chronic pain group and $91.2 \%$ for the no chronic pain group.

Table 7 presents the partial regression coefficients, the Wald tests, the odds ratios (OR) $[\operatorname{Exp}(B)]$, and the $95 \%$ confidence intervals $(C I)$ for ORs for each predictor. Significant predictors of chronic pain included pain catastrophizing $(\mathrm{OR}=1.09 ; 95 \% \mathrm{CI}=1.03-1.15)$ and current age $(\mathrm{OR}=1.13 ; 95 \% \mathrm{CI}=1.01-1.27)$ whereby for each single-point increase in the pain catastrophizing score, there was a 1.09 times greater likelihood of having chronic pain, controlling for all other variables in the model. With respect to current age, with each singlepoint increase in current age, there was a 1.13 times greater likelihood of having chronic pain. Higher scores reflected higher anxiety, depression, pain catastrophizing, PTSS, and cancer worry, and older current age and age at diagnosis.

\section{Discussion}


The aims of the current study were to identify rates and patterns of chronic pain among a population of survivors of childhood cancer; to describe multiple dimensions of pain among this population and to identify biological, clinical, and psychosocial predictors of chronic pain. The data suggest that approximately one in four survivors of childhood cancer experience chronic pain. While the rates of chronic pain in survivors may not be strikingly different than the general youth population (King et al., 2011), survivors may have unique needs as it relates to pain management when considering a history of cancer. For example, chronic pain is often comorbid with psychiatric conditions (Noel, Groenewald, et al., 2016) and other health concerns like increased disability (Palermo et al., 2016). Survivors of childhood cancer are at significant risk of developing both physical and psychological late effects as a result of their cancer or cancer treatment (Blaauwbroek et al., 2007; Twycross et al., 2015) and therefore may be at even greater risk of developing comorbid conditions.

Previous literature has found that while prevalence rates of chronic pain in youth is high, 5-8\% have moderate to severe pain problems based on the presence of chronic pain and scores of pain intensity and interference (Huguet \& Miro, 2008). These subsets of individuals are the youth whose lives are profoundly impacted by pain. Thus, it is important to identify this subgroup of survivors who may be suffering from a moderate to severe chronic pain problem. In our sample, $12.1 \%(n=17)$ of survivors were identified as experiencing high levels of pain intensity and high levels of pain interference, determined through our cluster analysis. Membership in this cluster corresponds with a severe chronic pain problem. Our third cluster identified survivors with chronic pain who reported moderate-to-high levels of pain interference and moderate levels of pain intensity, which accounted for 11 (7.9\%) survivors. These survivors can be considered to have a moderate chronic pain problem. Only 6 survivors (4.3\%) reported 
low levels of low levels of pain intensity and low levels of pain interference. These survivors are considered not to have a chronic pain problem. In sum, the cluster analysis found that 28 of 34 survivors with chronic pain had moderate to severe pain problems, which accounted for $20 \%$ of the overall sample of LTSCCs. This percentage is substantially higher than the 5-8\% of youth with chronic pain in the general population identified to have a moderate to severe chronic pain problem (Huguet \& Miro, 2008), meaning that those with a history of cancer may be at greater risk of suffering profoundly from chronic pain.

The most common location of chronic pain was reported to be in the muscles and joints followed by legs and 'other'. Interestingly, when asked to specify 'other', survivors listed locations such as the neck, back, and lower back. The locations indicated by survivors slightly differ from the general population, where it has been observed that the most common locations of chronic pain in youth is in the limbs, head, and abdomen (King et al., 2011). These differences may be due to cancer-specific comorbidities such as pain due to osteonecrosis caused by chemotherapy, neuropathic pain caused by radiation, or osteoporosis caused by steroids. In addition, individuals undergoing cancer treatment, particularly treatment for pediatric leukemia, often receive lumbar punctures in the same area of the spine repeatedly over the course of their treatment, and it is possible that these areas can become permanently sore when treatment has completed. Bowers and colleagues (2012) found that among 99 ALL survivors, 44\% reported having chronic back pain, though back pain was not explored in other diagnoses of survivors of childhood cancer. Surprisingly, there is a dearth of research that has explored the persistence of pain in survivors in body areas commonly linked to procedural pain during active cancer therapy. Interestingly, no survivors in the current sample reported experiencing chronic abdominal pain and there appeared to be an underrepresented sample of chronic headache. It is possible that 
survivors do not conceptualize headaches as 'pain' and instead consider it a separate entity. For this reason, it is also possible that chronic pain may be underreported in this population. Finally, the 'other' category could be capturing a type of widespread pain that is not captured by selecting only one location.

Survivors with chronic pain were generally older than survivors without chronic pain, suggesting that the older survivors were, the more likely they were to have chronic pain. Additionally, survivors with chronic pain were significantly older at diagnosis than survivors without chronic pain. These findings are contrary to other literature that shows pain is related to younger age at diagnosis (Cox et al., 2009; Lu et al., 2011; van Dijk et al., 2008), though none of these studies investigated the presence of chronic pain as defined in the current study. It is possible that older age at diagnosis being related to chronic pain can be explained by the ability to remember traumatic and painful experiences related to their cancer treatment. It is known that memories of painful experiences affect how children experience pain in the future in that children with negatively biased memories of painful experiences report higher pain intensity in subsequent painful experiences compared to youth with accurate or positively biased accounts of their past painful experiences (Noel et al., 2017). For a child who undergoes treatment at a younger age, their memories of procedures do not exist and therefore are not vulnerable to negative biases. Thus, youth who receive treatment at younger ages may be at decreased risk of developing chronic pain compared to survivors who have negatively biased memories of their cancer treatment. Non-significant sex differences may have been a result of the small sample of survivors with chronic pain as studies have consistently demonstrated that chronic pain is more prevalent in females than males in the general population (King et al., 2011). Additionally, past literature suggests that female survivors of childhood cancer report more pain than male 
survivors (Schulte et al., In Preparation). Non-significant findings may also suggest that sex does not play as big of a role in the development of chronic pain in this population, which is further evidence to suggest that more research is needed on chronic pain in LTSCCs, specifically. Surprisingly, many variables related to treatment and diagnosis were not related to the presence of chronic pain, suggesting that perhaps treatment (i.e., treatment intensity, radiation) and diagnosis (i.e., CNS tumors, leukemia) factors play less of a role in the development of chronic pain than do biological (i.e., age, sex) and psychosocial (i.e., anxiety, PTSS) variables.

Survivors living with chronic pain reported significantly higher anxiety, posttraumatic stress, and significantly worse quality of life compared to survivors without chronic pain. Although, survivors with versus without chronic pain did not differ significantly in cancer worry or depressive symptoms as a result of a more stringent alpha level. While non-significant, it appeared that survivors with chronic pain reported generally higher cancer worry and depression than survivors without chronic pain. Overall, it appears that survivors with chronic pain are significantly more compromised from a psychological perspective and likely require psychosocial support as a component of treatment for their chronic pain.

Current age and pain catastrophizing arose as significant predictors within the logistic regression model over and above anxiety, depression, sex, cancer worry, and age at diagnosis, suggesting that older current age and greater pain catastrophizing are important components related to chronic pain in survivors of childhood cancer. The predictive ability of pain catastrophizing supports the fear-avoidance model of pain such that those who experience pain who also engage in behaviors and cognitions that are known to exacerbate pain, may be at risk of developing a chronic pain problem (Asmundson et al., 2012). Furthermore, these findings support the model proposed by Heathcote and Eccleston (2017) where hypervigilance to pain 
could be related to fear and worry of cancer returning, which could in turn, exacerbate the pain, similar to the mutual maintenance model of pain and anxiety (Asmundson \& Katz, 2009).

\section{Strenghts and limitations}

The current study had several strengths. The inclusion of patient partners was central in refining the aims and hypotheses of the study, verifying the selection of measures, and interpreting the results. Collaborating with individuals with lived experiences ensured that the purpose of the study addressed an unmet need in this population and that the results were properly communicated in this initial knowledge translation phase. Additionally, the study utilized comprehensive measures to assess the complex, multidimensional nature of pain. This fills a gap among the existing literature which has focused primarily on the presence or absence of pain, pain intensity and/or interference without taking into account other facets of the pain experience.

The study was not without limitations, however. First, the study design was crosssectional in nature, preventing the ability to draw causal conclusions. Second, there was a relatively small sample of LTSCCs currently living with chronic pain and as a result, the sample is not considered to be representative of all survivors of childhood cancer living with chronic pain. Larger cohort studies are needed to identify the true prevalence and patterns of chronic pain along with its comorbidities. Third, while self-report is currently the gold standard in the assessment of pain, self-report is subject to reporting bias in measures of anxiety, depression, pain catastrophizing, quality of life, posttraumatic stress, and cancer worry. Fourth, the overall sample is not considered to be representative of all LTSCCs living in Canada because $90.3 \%$ of the sample was recruited from the Alberta Children's Hospital. Additionally, the most common types of childhood cancer diagnoses are leukemias and CNS tumors (Siegel et al., 2016). The 
most common diagnosis observed in the current sample were survivors of solid tumor (42.3\%) followed by survivors of leukemia (32.8\%), lymphoma (16.1\%), and CNS tumors (8.8\%). Many survivors of CNS tumors are followed by neuro-oncologists at the Alberta Children's Hospital rather than the Long-Term Survivor Clinic, where recruitement for the current study took place.

\section{Future directions}

There is currently a scarcity of research on multiple dimensions of pain in LTSCCs and thus more studies are needed that comprehensively assess pain in this population. Additionally, the literature on chronic pain in LTSCCs is even scarcer, and thus researchers are encouraged to explore chronic pain using its formal definition of pain lasting three months or longer. While the cluster analysis in the current study is informative in beginning research into the exploration of the magnitude of chronic pain problems, future research should utilize much larger samples of LTSCCs with chronic pain in order to more reliably identify cluster membership. The difference in pain locations between those with a history of cancer and the general population of youth with chronic pain supports the notion that LTSCCs need to be studied separately from youth with chronic non-cancer pain. Those with a history of cancer are a unique population whose pain history could be due to numerous causes. On the other hand, our sample showed several similarities to chronic non-cancer pain populations, such as the relationship to pscychosocial outcomes, suggesting that models tested in chronic non-cancer pain populations may also have relevance to LTSCCs. In terms of capturing pain location, future research should inquire about all pain locations using a body map (Foxen-Craft et al., 2019) as well as consider including measures of widespread pain (Dudeney, Law, Meyyappan, Palermo, \& Rabbitts, 2019). The distinction between pain phenotypes, such as those due to central sensitization, is imperative in the selection of appropriate interventions (Woolf, 2011). Furthermore, to increase participation 
from survivors of CNS tumors in order to create a more representative sample, it is recommended that future research intentionally seek out clinics that follow these types of survivors.

Longitudinal research is needed to understand the directionality of the relationships between chronic pain and other variables. Generally, the biopsychosocial model of pain suggests that these relationships are bidirectional such that pain affects and is affected by biological, psychological, and social factors. It is currently unknown whether the presence of chronic pain puts survivors at increased risk of developing subsequent mental health problems or if certain mental health problems put survivors at risk of developing chronic pain. Furthermore, there could be underlying variables that put survivors at risk of developing both and it is also possible that pain and psychosocial factors mutually maintain each other. Longitudinal research would also increase our ability to test the more nuanced interrelationships of these variables, such as mediation models of pain catastrophizing, pain interference, and PTSS previously tested in chronic non-cancer pain populations (Neville, Soltani, Pavlova, \& Noel, 2018). Research of this nature would be more useful in identifying modifiable mechanisms to target in interventions for LTSCCs. Finally, longitudinal research that begins at the time of diagnosis and extends into long-term survivorship could answer important questions about whether certain variables put survivors at risk for developing subsequent chronic pain problems and eventually identify strategies to help prevent it.

Further research is also needed on interventions for LTSCCs living with chronic pain, as no studies to date have investigated this. Cognitive behavioral interventions have been effective in the treatment of chronic pain as well as its psychosocial consequences. These interventions have been successfully translated to self-guided web-based interventions to reduce major barriers 
to obtaining necessary treatment (Palermo et al., 2016), but have not yet been tested on survivors of childhood cancer. Demonstrating that an intervention of this nature is feasible and effective has the potential to revolutionize treatments for LTSCCs to ameliorate late-effects of treatment.

\section{Clinical Implications}

There are several clinical implications based on the findings. The data show that chronic pain is a prevalent issue in this population and that a staggering amount of survivors have modertate to severe chronic pain problems. With evidence to suggest such a large group of survivors reporting chronic pain have moderate to severe chronic pain problems, it is imperative that survivors are not only screened for the presence of chronic pain in their long-term follow-up visits, but are also evaluated for the magnitude of their pain problem. As such, it would be important to inquire about the average intensity of their pain as well as how much pain interferes in their life. Furthermore, it was found that survivors who reported having chronic pain were psychosocially worse-off than survivors without chronic pain. These findings support additional assessment of the consequences shown to be associated with chronic pain in this population. Survivors reporting a moderate to severe pain problem and/or survivors who report psychosocial difficulties along with their chronic pain may benefit from referral to tertiary pain clinics, which house multidisciplinary teams consisting of physical therapists, psychologists, and physicians specifically trained in treating chronic pain.

\section{Conclusions}

This research added to our current understanding of pain in survivors of childhood cancer. The study addresses an important gap in the current literature by comprehensively examining pain and psychosocial outcomes in survivors of childhood cancer. The data suggest that a subset of survivors reported having chronic pain, which is known to be a significant health 
concern, and approximately one in five survivors reported a moderate to severe chronic pain problem. Furthermore, it was found that survivors with chronic pain reported worse psychosocial outcomes than survivors without chronic pain, meaning that regardless of the directionality of this relationship, survivors with chronic pain are worse off psychosocially than survivors without chronic pain. Older current age and greater pain catastrophizing emerged as the strongest predictors of chronic pain, suggesting that in some ways, survivors of childhood cancer with chronic pain are similar to the general youth population and thus models used in chronic noncancer pain should be tested on LTSCCs. Findings support regular screening for the presence and magnitude of chronic pain problems in long-term follow-up clinics. 


\section{References}

American Cancer Society (2019). Cancer Facts \& Figures. Retrieved from

https://www.cancer.org/research/cancer-facts-statistics/all-cancer-facts-figures/cancer-factsfigures-2019.html

American Psychiatric Association (2000). Diagnostic and statistical manual of mental disorders (4th ed., text rev.). Washington, DC.

American Psychiatric Association (2013). Diagnostic and statistical manual of mental disorders (5th ed.). Arlington, VA.

Alberts, N. M., Gagnon, M. M., \& Stinson, J. N. (2018). Chronic pain in survivors of childhood cancer: a developmental model of pain across the cancer trajectory. Pain, 159(10), 19161927. doi:10.1097/j.pain.0000000000001261

Alessi, D., Dama, E., Barr, R., Mosso, M. L., Maule, M., Magnani, C., .. Merletti, F. (2007). Health-related quality of life of long-term childhood cancer survivors: a population-based study from the Childhood Cancer Registry of Piedmont, Italy. Eur J Cancer, 43(17), 2545-2552. doi:10.1016/j.ejca.2007.07.026

Arpaci, T., \& Kilicarslan Toruner, E. (2016). Assessment of problems and symptoms in survivors of childhood acute lymphoblastic leukaemia. Eur J Cancer Care (Engl), 25(6), 1034-1043. doi:10.1111/ecc.12561

Ashbaugh, A. R., Houle-Johnson, S., Herbert, C., El-Hage, W., \& Brunet, A. (2016). Psychometric Validation of the English and French Versions of the Posttraumatic Stress Disorder Checklist for DSM-5 (PCL-5). PLoS One, 11(10), e0161645. doi:10.1371/journal.pone.0161645 
Asmundson, G. J., \& Katz, J. (2009). Understanding the co-occurrence of anxiety disorders and chronic pain: state-of-the-art. Depress Anxiety, 26(10), 888-901. doi:10.1002/da.20600

Asmundson, G. J., Noel, M., Petter, M., \& Parkerson, H. A. (2012). Pediatric fear-avoidance model of chronic pain: Foundation, application and future directions. Pain Research and Management, 17(6), 397-405. doi:10.1155/2012/908061

Bennett, M. I., Kaasa, S., Barke, A., Korwisi, B., Rief, W., Treede, R. D., \& Pain, I. T. f. t. C. o. C. (2019). The IASP classification of chronic pain for ICD-11: chronic cancer-related pain. Pain, 160(1), 38-44. doi:10.1097/j.pain.0000000000001363

Blaauwbroek, R., Groenier, K. H., Kamps, W. A., Meyboom-de Jong, B., \& Postma, A. (2007). Late effects in adult survivors of childhood cancer: the need for life-long follow-up. Ann Oncol, 18(11), 1898-1902. doi:10.1093/annonc/mdm336

Blevins, C. A., Weathers, F. W., Davis, M. T., Witte, T. K., \& Domino, J. L. (2015). The Posttraumatic Stress Disorder Checklist for DSM-5 (PCL-5): Development and Initial Psychometric Evaluation. J Trauma Stress, 28(6), 489-498. doi:10.1002/jts.22059

Bowers, D. C., Griffith, T., Gargan, L., Cochran, C., Kleiber, B., Foxwell, A., . . Germann, J. (2012). Back Pain Among Long-term Survivors of Childhood Leukemia. Journal of Pediatric Hematology and Oncology, 34, 624-629.

Brinkman, T. M., Ullrich, N. J., Zhang, N., Green, D. M., Zeltzer, L. K., Lommel, K. M., .. . Krull, K. R. (2013). Prevalence and predictors of prescription psychoactive medication use in adult survivors of childhood cancer: a report from the Childhood Cancer Survivor Study. J Cancer Surviv, 7(1), 104-114. doi:10.1007/s11764-012-0250-x

Castarlenas, E., Jensen, M. P., von Baeyer, C. L., \& Miro, J. (2017). Psychometric Properties of the Numerical Rating Scale to Assess Self-Reported Pain Intensity in Children and 
Adolescents: A Systematic Review. Clin J Pain, 33(4), 376-383.

doi:10.1097/AJP.0000000000000406

Cella, D., Riley, W., Stone, A., Rothrock, N., Reeve, B., Yount, S., . . Group, P. C. (2010). The Patient-Reported Outcomes Measurement Information System (PROMIS) developed and tested its first wave of adult self-reported health outcome item banks: 2005-2008. J Clin Epidemiol, 63(11), 1179-1194. doi:10.1016/j.jclinepi.2010.04.011

Cox, C. L., Montgomery, M., Oeffinger, K. C., Leisenring, W., Zeltzer, L., Whitton, J. A., . . . Robison, L. L. (2009). Promoting physical activity in childhood cancer survivors: results from the Childhood Cancer Survivor Study. Cancer, 115(3), 642-654. doi:10.1002/cncr.24043

Crom, D., Smith, D., Xiong, Z., Onar, A., Hudson, M. M., Merchant, T. E., \& Morris, E. B. (2010). Health Status in Long-term Survivors of Pediatric Craniopharyngiomas. Journal of Neuroscience Nursing, 42(6), 323-330.

Crombez, G., Bijttebier, P., Eccleston, C., Mascagni, T., Mertens, G., Goubert, L., \& Verstraeten, K. (2003). The child version of the pain catastrophizing scale (PCS-C): a preliminary validation. Pain, 104(3), 639-646. doi:10.1016/s0304-3959(03)00121-0

Cummings, E. A., Reid, G. J., Finley, G. A., McGrath, P. J., \& Ritchie, J. A. (1996). Prevalence and source of pain in pediatric inpatients. Pain, 25-31.

Custers, J. A., Gielissen, M. F. M., Janssen, S. H. V., de Wilt, J. H. W., \& Prins, J. B. (2016). Fear of cancer recurrence in colorectal cancer survivors. Support Care Cancer, 24(2), 555-562. doi:10.1007/s00520-015-2808-4

Custers, J. A., Tielen, R., Prins, J. B., de Wilt, J. H., Gielissen, M. F., \& van der Graaf, W. T. (2015). Fear of progression in patients with gastrointestinal stromal tumors (GIST): Is 
extended lifetime related to the Sword of Damocles? Acta Oncol, 54(8), 1202-1208. doi:10.3109/0284186X.2014.1003960

Custers, J. A., van den Berg, S. W., van Laarhoven, H. W., Bleiker, E. M., Gielissen, M. F., \& Prins, J. B. (2014). The Cancer Worry Scale: detecting fear of recurrence in breast cancer survivors. Cancer Nurs, 37(1), E44-50. doi:10.1097/NCC.0b013e3182813a17

D'Agostino, N. M., Edelstein, K., Zhang, N., Recklitis, C. J., Brinkman, T. M., Srivastava, D., . . . Krull, K. R. (2016). Comorbid symptoms of emotional distress in adult survivors of childhood cancer. Cancer, 122(20), 3215-3224. doi:10.1002/cncr.30171

Dudeney, J., Law, E. F., Meyyappan, A., Palermo, T. M., \& Rabbitts, J. A. (2019). Evaluating the psychometric properties of the Widespread Pain Index and the Symptom Severity scale in youth with painful conditions. Can J Pain, 3(1), 137-147.

doi:10.1080/24740527.2019.1620097

Engel, G. L. (1977). The need for a new medical model - a challenge for biomedicine. Science, 196(4286).

Fales, J. L., Murphy, L. K., Rights, J. D., \& Palermo, T. M. (2019). Daily Peer Victimization Experiences of Adolescents With and Without Chronic Pain: Associations With Mood, Sleep, Pain, and Activity Limitations. J Pain. doi:10.1016/j.jpain.2019.05.016

Finnegan, L., Campbell, R. T., Ferrans, C. E., Wilbur, J., Wilkie, D. J., \& Shaver, J. (2009). Symptom cluster experience profiles in adult survivors of childhood cancers. J Pain Symptom Manage, 38(2), 258-269. doi:10.1016/j.jpainsymman.2008.09.010

Foa, E. B., Johnson, K. M., Feeny, N. C., \& Treadwell, K. R. (2001). The child PTSD Symptom Scale: a preliminary examination of its psychometric properties. J Clin Child Psychol, 30(3), 376-384. doi:10.1207/S15374424JCCP3003_9 
Foxen-Craft, E., Scott, E. L., Kullgren, K. A., Philliben, R., Hyman, C., Dorta, M., .. . VoepelLewis, T. (2019). Pain location and widespread pain in youth with orthopaedic conditions: Exploration of the reliability and validity of a body map. Eur J Pain, 23(1), 57-65. doi:10.1002/ejp.1282

Green, C. R., Hart-Johnson, T., \& Loeffler, D. R. (2011). Cancer-related chronic pain: examining quality of life in diverse cancer survivors. Cancer, 117(9), 1994-2003. doi:10.1002/cncr.25761

Heathcote, L. C., \& Eccleston, C. (2017). Pain and cancer survival: a cognitive-affective model of symptom appraisal and the uncertain threat of disease recurrence. Pain, 158(7), 11871191. doi:10.1097/j.pain.0000000000000872

Hinds, P. S., Nuss, S. L., Ruccione, K. S., Withycombe, J. S., Jacobs, S., DeLuca, H., . . DeWalt, D. A. (2013). PROMIS pediatric measures in pediatric oncology: valid and clinically feasible indicators of patient-reported outcomes. Pediatr Blood Cancer, 60(3), 402-408. doi: $10.1002 / p b c .24233$

Hudson, M. M., Mertens, A., Yasui, Y., Hobbie, W. L., Chen, H., Gurney, J. G., . . Oeffinger, K. C. (2003). Health status of adult long-term survivors of childhoood cancer: A report from the childhood cancer survivor study. Journal the American Medical Association, 290(12), 1583-1592.

Huguet, A., \& Miro, J. (2008). The severity of chronic pediatric pain: an epidemiological study. J Pain, 9(3), 226-236. doi:10.1016/j.jpain.2007.10.015

Johannsdottir, I. M. R., Hamre, H., Fossa, S. D., Loge, J. H., Drolsum, L., Lund, M. B., . . . Kiserud, C. (2017). Adverse Health Outcomes and Associations with Self-Reported 
General Health in Childhood Lymphoma Survivors. J Adolesc Young Adult Oncol, 6(3), 470-476. doi:10.1089/jayao.2017.0018

Kazak, A. E., Hocking, M. C., Ittenbach, R. F., Meadows, A. T., Hobbie, W., DeRosa, B. W., . . Reilly, A. (2012). A revision of the intensity of treatment rating scale: classifying the intensity of pediatric cancer treatment. Pediatr Blood Cancer, 59(1), 96-99. doi:10.1002/pbc. 23320

King, S., Chambers, C. T., Huguet, A., MacNevin, R. C., McGrath, P. J., Parker, L., \& MacDonald, A. J. (2011). The epidemiology of chronic pain in children and adolescents revisited: a systematic review. Pain, 152(12), 2729-2738. doi:10.1016/j.pain.2011.07.016

Klassen, A. F., Rosenberg-Yunger, Z. R., D'Agostino, N. M., Cano, S. J., Barr, R., Syed, I., . . . Nathan, P. C. (2015). The development of scales to measure childhood cancer survivors' readiness for transition to long-term follow-up care as adults. Health Expect, 18(6), 19411955. doi:10.1111/hex.12241

Lee, I., Garland, S. N., DeMichele, A., Farrar, J. T., Im, E. O., \& Mao, J. J. (2017). A crosssectional survey of pain catastrophising and acupuncture use among breast cancer survivors. Acupunct Med, 35(1), 38-43. doi:10.1136/acupmed-2016-011056

Lu, Q., Krull, K. R., Leisenring, W., Owen, J. E., Kawashima, T., Tsao, J. C., . . Zeltzer, L. K. (2011). Pain in long-term adult survivors of childhood cancers and their siblings: a report from the Childhood Cancer Survivor Study. Pain, 152(11), 2616-2624. doi:10.1016/j.pain.2011.08.006

Macartney, G., VanDenKerkhof, E., Harrison, M. B., \& Stacey, D. (2014). Symptom experience and quality of life in pediatric brain tumor survivors: a cross-sectional study. J Pain Symptom Manage, 48(5), 957-967. doi:10.1016/j.jpainsymman.2013.12.243 
Marina, N., Hudson, M. M., Jones, K. E., Mulrooney, D. A., Avedian, R., Donaldson, S. S., . . Ness, K. K. (2013). Changes in Health Status Among Aging Survivors of Pediatric Upper and Lower Extremity Sarcoma: A Report From the Childhood Cancer Survivor Study. Archives of Physical Medicine and Rehabilitation, 94(6), 1062-1073. doi:10.1016/j.apmr.2013.01.013

McGrath, P. A. (1990). Pain in children: Nature, assessment, and treatment. New York: Guilford. Meeske, K. A., Siegel, S. E., Globe, D. R., Mack, W. J., \& Bernstein, L. (2005). Prevalence and correlates of fatigue in long-term survivors of childhood leukemia. J Clin Oncol, 23(24), 5501-5510. doi:10.1200/JCO.2005.03.210

Mertens, A. C., Sencer, S., Myers, C. D., Recklitis, C., Kadan-Lottick, N., Whitton, J., . . . Zeltzer, L. (2008). Complementary and alternative therapy use in adult survivors of childhood cancer: a report from the Childhood Cancer Survivor Study. Pediatr Blood Cancer, 50(1), 90-97. doi:10.1002/pbc.21177

Neville, A., Soltani, S., Pavlova, M., \& Noel, M. (2018). Unravelling the Relationship Between Parent and Child PTSD and Pediatric Chronic Pain: the Mediating Role of Pain Catastrophizing. J Pain, 19(2), 196-206. doi:10.1016/j.jpain.2017.10.004

Noel, M., Groenewald, C. B., Beals-Erickson, S. E., Gebert, J. T., \& Palermo, T. M. (2016). Chronic pain in adolescence and internalizing mental health disorders: a nationally representative study. Pain, 157(6), 1333-1338. doi:10.1097/j.pain.0000000000000522

Noel, M., Rabbitts, J. A., Fales, J., Chorney, J., \& Palermo, T. M. (2017). The influence of pain memories on children's and adolescents' post-surgical pain experience: A longitudinal dyadic analysis. Health Psychol, 36(10), 987-995. doi:10.1037/hea0000530 
Noel, M., Wilson, A. C., Holley, A. L., Durkin, L., Patton, M., \& Palermo, T. M. (2016). Posttraumatic stress disorder symptoms in youth with vs without chronic pain. Pain, 157(10), 2277-2284. doi:10.1097/j.pain.0000000000000642

Oancea, S. C., Brinkman, T. M., Ness, K. K., Krull, K. R., Smith, W. A., Srivastava, D. K., . . . Gurney, J. G. (2014). Emotional distress among adult survivors of childhood cancer. $J$ Cancer Surviv, 8(2), 293-303. doi:10.1007/s11764-013-0336-0

Palermo, T. M., Law, E. F., Fales, J., Bromberg, M. H., Jessen-Fiddick, T., \& Tai, G. (2016). Internet-delivered cognitive-behavioral treatment for adolescents with chronic pain and their parents: a randomized controlled multicenter trial. Pain, 157(1), 174-185. doi:10.1097/j.pain.0000000000000348

Patton, M., Racine, N., Afzal, A. R., Russell, K. B., Forbes, C., Trepanier, L., .. . Schulte, F. (In Preparation). The pain of survival: an examination of prevalence, patterns, and predictors of pain in survivors of childhood cancer.

Pogany, L., Barr, R. D., Shaw, A., Speechley, K. N., Barrera, M., \& Maunsell, E. (2006). Health status in survivors of cancer in childhood and adolescence. Qual Life Res, 15(1), 143157. doi:10.1007/s11136-005-0198-7

Prasertsri, N., Holden, J., Keefe, F. J., \& Wilkie, D. J. (2011). Repressive coping style: relationships with depression, pain, and pain coping strategies in lung cancer outpatients. Lung Cancer, 71(2), 235-240. doi:10.1016/j.lungcan.2010.05.009

Rabbitts, J. A., Fisher, E., Rosenbloom, B. N., \& Palermo, T. M. (2017). Prevalence and Predictors of Chronic Postsurgical Pain in Children: A Systematic Review and MetaAnalysis. J Pain, 18(6), 605-614. doi:10.1016/j.jpain.2017.03.007 
Recklitis, C. J., Liptak, C., Footer, D., Fine, E., Chordas, C., \& Manley, P. (2019). Prevalence and Correlates of Pain in Adolescent and Young Adult Survivors of Pediatric Brain Tumors. J Adolesc Young Adult Oncol. doi:10.1089/jayao.2019.0029

Sadighi, Z. S., Ness, K. K., Hudson, M. M., Morris, E. B., Ledet, D. S., Pui, C. H., . . Khan, R. B. (2014). Headache types, related morbidity, and quality of life in survivors of childhood acute lymphoblastic leukemia: a prospective cross sectional study. Eur J Paediatr Neurol, 18(6), 722-729. doi:10.1016/j.ejpn.2014.06.006

Schulte, F. P., M., Alberts, N. M., Kunin-Batson, A., Olson-Bullis, B., Forbes, C., Russell, K. B., ... Krull, K. R. (In Preparation). Pain in long-term survivors of childhood cancer: a systematic review of the current state of knowledge and a call to action from the Children's Oncology Group.

Schultz, K. A., Chen, L., Chen, Z., Kawashima, T., Oeffinger, K. C., Woods, W. G., . . Neglia, J. P. (2014). Health conditions and quality of life in survivors of childhood acute myeloid leukemia comparing post remission chemotherapy to BMT: a report from the children's oncology group. Pediatr Blood Cancer, 61(4), 729-736. doi:10.1002/pbc.24881

Siegel, R. L., Miller, K. D., \& Jemal, A. (2016). Cancer statistics, 2016. CA Cancer J Clin, 66(1), 7-30. doi:10.3322/caac.21332

Stewart, R. W., Ebesutani, C., Drescher, C. F., \& Young, J. (2017). The Child PTSD Symptom Scale: An Investigation of Its Psychometric Properties. J Interpers Violence, 32(15), 2237-2256. doi:10.1177/0886260515596536

Thewes, B., Lebel, S., Seguin Leclair, C., \& Butow, P. (2016). A qualitative exploration of fear of cancer recurrence (FCR) amongst Australian and Canadian breast cancer survivors. Support Care Cancer, 24(5), 2269-2276. doi:10.1007/s00520-015-3025-x 
Treede, R. D., Rief, W., Barke, A., Aziz, Q., Bennett, M. I., Benoliel, R., .. Wang, S. J. (2015). A classification of chronic pain for ICD-11. Pain, 156(6), 1003-1007. doi:10.1097/j.pain.0000000000000160

Twycross, A., Parker, R., Williams, A., \& Gibson, F. (2015). Cancer-Related Pain and Pain Management: Sources, Prevalence, and the Experiences of Children and Parents. $J$ Pediatr Oncol Nurs, 32(6), 369-384. doi:10.1177/1043454214563751

van de Wal, M., van Oort, I., Schouten, J., Thewes, B., Gielissen, M., \& Prins, J. (2016). Fear of cancer recurrence in prostate cancer survivors. Acta Oncol, 55(7), 821-827. doi:10.3109/0284186X.2016.1150607

van den Beuken-van Everdingen, M. H., Hochstenbach, L. M., Joosten, E. A., Tjan-Heijnen, V. C., \& Janssen, D. J. (2016). Update on Prevalence of Pain in Patients With Cancer: Systematic Review and Meta-Analysis. J Pain Symptom Manage, 51(6), 1070-1090 e1079. doi:10.1016/j.jpainsymman.2015.12.340

van Dijk, E. M., van Dulmen-den Broeder, E., Kaspers, G. J., van Dam, E. W., Braam, K. I., \& Huisman, J. (2008). Psychosexual functioning of childhood cancer survivors. Psychooncology, 17(5), 506-511. doi:10.1002/pon.1274

Varni, J. W. (1996). Family functioning predictors of adjustment in children with newly diagnosed cancer: a prospective analysis. Journal of Child Psychology and Psychiatry, 37(3), 321-328.

Varni, J. W., Seid, M., \& Kurtin, P. S. (2001). PedsQL ${ }^{\text {TM }}$ 4.0: Reliability and Validity of the Pediatric Quality of Life Inventory ${ }^{\mathrm{TM}}$ Version 4.0 Generic Core Scales in Healthy and Patient Populations. Medical Care, 39(8), 800-812. 
Vlaeyen, J. W., \& Linton, S. J. (2000). Fear-avoidance and its consequences in chronic muskuloskeletal pain: a state of the art. Pain, 85, 317-332.

von Baeyer, C. L., Spagrud, L. J., McCormick, J. C., Choo, E., Neville, K., \& Connelly, M. A. (2009). Three new datasets supporting use of the Numerical Rating Scale (NRS-11) for children's self-reports of pain intensity. Pain, 143(3), 223-227.

doi:10.1016/j.pain.2009.03.002

Woolf, C. J. (2011). Central sensitization: implications for the diagnosis and treatment of pain. Pain, 152(3 Suppl), S2-15. doi:10.1016/j.pain.2010.09.030 


\section{Table 1}

Demographic Characteristics

\begin{tabular}{lcccc}
\hline & $\begin{array}{c}\text { All Survivors } \\
(n=138)\end{array}$ & $\begin{array}{c}\text { Survivors with } \\
\text { Chronic Pain } \\
(n=36)\end{array}$ & $\begin{array}{c}\text { Survivors } \\
\text { without } \\
\text { Chronic Pain } \\
(n=102)\end{array}$ & $p$ \\
\hline Current Age $^{\dagger}$ & $17.20(4.90)$ & $18.64(4.72)$ & $16.79(4.87)$ & $\mathbf{. 0 5 0}$ \\
Sex $^{\dagger}$ & 68 & $13(19.1)$ & $53(77.8)$ & .120 \\
$\quad$ Male & 72 & $23(31.9)$ & $48(66.7)$ & \\
$\quad$ Female & & & \\
Ethnicity & 96 & $24(25.0)$ & $72(75.0)$ & .459 \\
$\quad$ Caucasian & 25 & $8(32.0)$ & $17(68.0)$ & \\
$\quad$ Other & & & & \\
${ }^{\dagger} \mathrm{M}(\mathrm{SD})$ & & &
\end{tabular}


Table 2

Demographic Characteristics of Survivors $<18$ Years Old

\begin{tabular}{|c|c|c|c|c|}
\hline & $\begin{array}{c}\text { All } \\
\text { Survivors } \\
<18 \text { years } \\
(n=61)\end{array}$ & $\begin{array}{l}\text { Survivors with } \\
\text { Chronic Pain } \\
\quad(n=13)\end{array}$ & $\begin{array}{c}\text { Survivors } \\
\text { without } \\
\text { Chronic Pain } \\
(n=48)\end{array}$ & $p$ \\
\hline \multicolumn{5}{|l|}{$\begin{array}{l}\text { Household Income } \\
(n=61)\end{array}$} \\
\hline$<\$ 90,000$ & 27 & $6(22.2)$ & $21(77.8)$ & .560 \\
\hline$>\$ 90,000$ & 34 & $7(20.6)$ & $27(79.4)$ & - \\
\hline \multicolumn{5}{|l|}{ Maternal Education } \\
\hline Grades 1-12 & 9 & $2(22.2)$ & $7(77.8)$ & - \\
\hline Some College & 16 & $1(0.1)$ & $15(93.8)$ & - \\
\hline Some University & 3 & $1(33.3)$ & $2(66.7)$ & - \\
\hline Technical Certification & 10 & $0(0.0)$ & $10(100.0)$ & - \\
\hline Undergraduate Degree & 13 & $6(46.2)$ & $7(53.8)$ & - \\
\hline $\begin{array}{l}\text { Graduate/Professional } \\
\text { Degree }\end{array}$ & 10 & $3(30.0)$ & $7(70.0)$ & - \\
\hline \multicolumn{5}{|l|}{ Paternal Education } \\
\hline Grades 1-12 & 12 & $1(8.3)$ & $11(91.7)$ & - \\
\hline Some College & 3 & $0(0.0)$ & $3(100.0)$ & - \\
\hline Some University & 7 & $2(28.6)$ & $5(71.4)$ & - \\
\hline Technical Certification & 14 & $0(0.0)$ & $14(100.0)$ & - \\
\hline Undergraduate Degree & 9 & $5(55.6)$ & $4(44.4)$ & - \\
\hline $\begin{array}{l}\text { Graduate/Professional } \\
\text { Degree }\end{array}$ & 16 & $5(31.3)$ & $11(68.8)$ & - \\
\hline
\end{tabular}

${ }^{7} \mathrm{~N}(\%)$ 


\section{Table 3}

Pain Outcomes

\begin{tabular}{|c|c|c|c|c|}
\hline & All Survivors & $\begin{array}{l}\text { Survivors with } \\
\text { Chronic Pain }\end{array}$ & $\begin{array}{l}\text { Survivors without } \\
\text { Chronic Pain }\end{array}$ & $p$ \\
\hline Chronic Pain (yes) ${ }^{\ddagger}$ & $36(26.1)$ & - & - & - \\
\hline Frequency $^{\dagger}(n=139)$ & $1.09(1.34)$ & $2.58(1.18)$ & - & - \\
\hline Intensity $^{\dagger}(n=69)$ & $4.33(1.95)$ & $4.79(1.57)$ & - & - \\
\hline $\operatorname{Duration}^{\dagger}(n=69)$ & $1.26(1.16)$ & $1.74(1.11)$ & - & - \\
\hline $\operatorname{Distress}^{\dagger}(n=69)$ & $1.48(0.85)$ & $1.79(0.69)$ & - & - \\
\hline $\begin{array}{l}\text { Interference }^{\dagger *} \\
(n=138)\end{array}$ & $0.00(1.00)$ & $0.89(0.98)$ & $-.31(.79)$ & $<.001$ \\
\hline 4-item $(n=69)$ & $7.75(4.42)$ & $11.60(4.22)$ & - & - \\
\hline 8 -item $(n=69)$ & $13.38(7.05)$ & $19.76(7.23)$ & - & - \\
\hline $\operatorname{Location}^{+}(n=69)$ & & & - & - \\
\hline Muscles/joints & $32(46.4)$ & $17(50.0)$ & - & - \\
\hline Legs & $14(20.3)$ & $6(17.6)$ & - & - \\
\hline Other & $10(14.5)$ & $7(20.6)$ & - & - \\
\hline Head & $9(5.8)$ & $4(11.8)$ & - & - \\
\hline Stomach & $4(5.8)$ & $0(.0)$ & - & - \\
\hline Chest & $0(0.0)$ & $0(0.0)$ & - & - \\
\hline
\end{tabular}

*Pain interference was collected with the four-item PROMIS measure (scale of 4-20) for survivors $<18$ years and eight-item PROMIS measure (scale of 8-40) for survivors $\geq 18$ years. Standardized scores were used to combine the data for the whole sample.

${ }^{\dagger} \mathrm{M}(\mathrm{SD})$

$\mathrm{N}(\%)$ 


\section{Table 4}

Chronic Pain, Pain Intensity, and Pain Interference Cluster Analysis

\begin{tabular}{lccc}
\hline & \multicolumn{3}{c}{ Cluster } \\
Variable & 1 & 2 & 3 \\
\hline Pain interference & 1.95 & -0.21 & 0.79 \\
Pain intensity & 1.00 & -0.86 & 0.13 \\
\hline Note: Scores of pain interference and pain intensity were converted to standardized z-scores.
\end{tabular}

Note: Scores of pain interference and pain intensity were converted to standardized z-scores. 


\section{Table 5}

Differences in Psychosocial, Treatment, and Diagnosis Variables in Survivors with versus without Chronic Pain

\begin{tabular}{|c|c|c|c|c|}
\hline & $\begin{array}{l}\text { All Survivors } \\
\quad(n=140)\end{array}$ & $\begin{array}{l}\text { Survivors with } \\
\text { Chronic Pain } \\
(n=36)\end{array}$ & $\begin{array}{l}\text { Survivor without } \\
\text { Chronic Pain } \\
(n=104)\end{array}$ & $p$ \\
\hline Cancer worry $^{\dagger}$ & $13.28(4.79)$ & $15.19(5.04)$ & $12.61(4.54)$ & .011 \\
\hline Depression $^{\dagger}$ & $15.42(8.04)$ & $18.31(8.17)$ & $14.40(7.78)$ & .014 \\
\hline Anxiety $^{\dagger}$ & $16.01(7.52)$ & $19.78(8.11)$ & $14.68(6.87)$ & $<.001$ \\
\hline Quality of life ${ }^{\dagger}$ & $75.61(14.95)$ & $61.26(11.15)$ & $80.67(12.69)$ & $<.001$ \\
\hline Posttraumatic stress ${ }^{* \dagger}$ & $-0.01(0.96)$ & $0.43(1.00)$ & $-0.17(.90)$ & .001 \\
\hline Pain catastrophizing $^{\dagger}$ & $11.24(9.04)$ & $16.00(9.41)$ & $9.56(8.32)$ & $<.001$ \\
\hline Treatment Intensity ${ }^{\dagger}$ & $2.65(0.83)$ & $2.74(0.73)$ & $2.62(0.87)$ & .467 \\
\hline Surgery (yes) & 87 & $23(65.7)$ & $64(63.4)$ & .803 \\
\hline Radiation $(\text { yes })^{\ddagger}$ & 44 & $10(28.6)$ & $34(33.7)$ & .579 \\
\hline Transplant (yes) ${ }^{\ddagger}$ & 17 & $3(9.4)$ & $14(15.4)$ & .397 \\
\hline Age at diagnosis ${ }^{\dagger}$ & $6.26(4.90)$ & $7.96(5.61)$ & $5.74(4.54)$ & .027 \\
\hline Time off treatment ${ }^{\dagger}$ & $9.89(4.81)$ & $9.74(4.75)$ & $9.90(4.86)$ & .871 \\
\hline \multicolumn{5}{|l|}{ Diagnosis $^{\ddagger}$} \\
\hline Leukemia & 45 & $11(24.4)$ & $32(71.1)$ & - \\
\hline Solid tumors & 58 & $14(24.1)$ & $44(75.9)$ & - \\
\hline CNS tumors & 12 & $3(25.0)$ & $9(75.0)$ & - \\
\hline Lymphoma & 22 & $7(31.8)$ & $15(68.2)$ & - \\
\hline \multicolumn{5}{|c|}{$\begin{array}{l}* P T S S \text { was measured using the CPSS for survivors }<18 \text { years and the PCL-5 for survivors } \geq 18 \\
\text { years. Scores were standardized to allow for combination of the data collected from both } \\
\text { measures. } \\
{ }^{\dagger} \mathrm{M}(\mathrm{SD})\end{array}$} \\
\hline
\end{tabular}




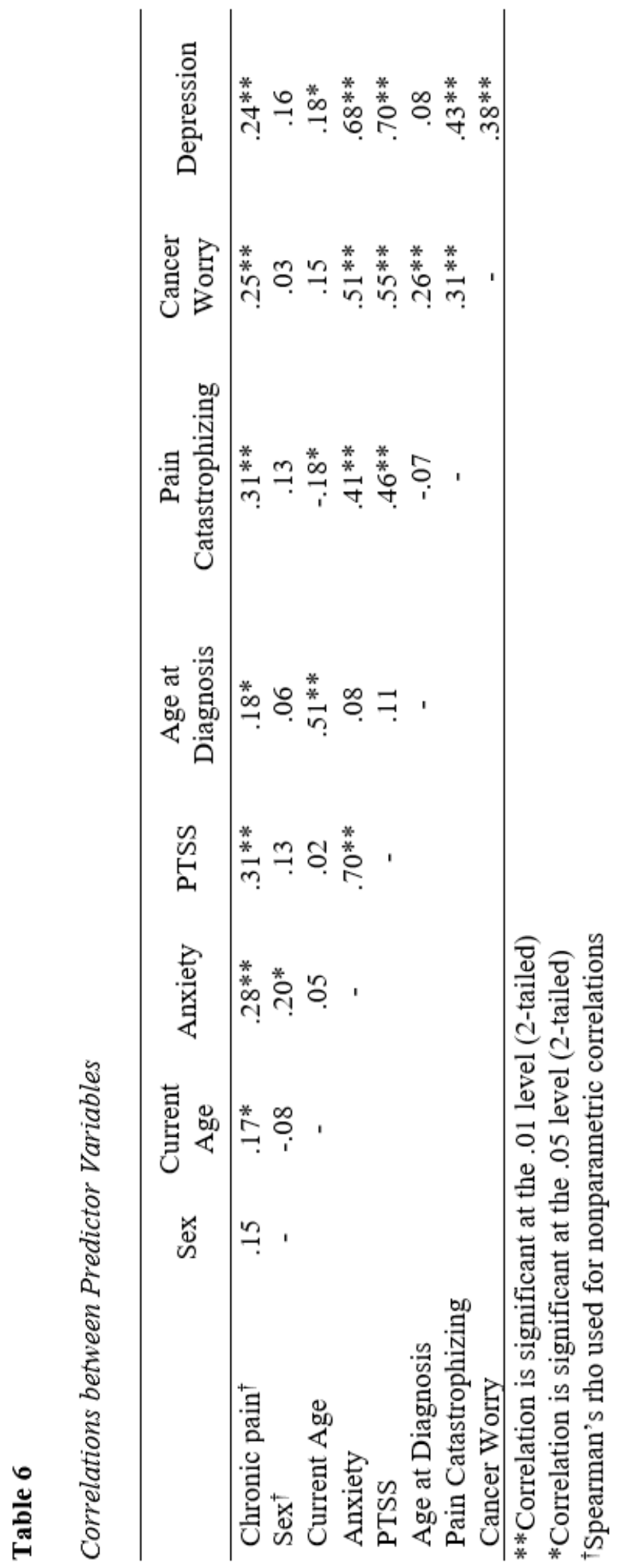


Table 7

Predictors of Chronic Pain

\begin{tabular}{lccccccc}
\hline Model & $b$ & $S E-b$ & Wald & $d f$ & $\operatorname{Exp}(\mathrm{B})$ & $95 \%$ CI Exp (B) & $p$ \\
\hline Intercept & -5.11 & 1.56 & 10.80 & 1 & .006 & & .001 \\
Current age & 0.13 & 0.06 & 4.42 & 1 & 1.13 & $1.00-1.27$ & $\mathbf{. 0 3 5}$ \\
Sex & 0.45 & 0.48 & 0.89 & 1 & 1.57 & $0.62-4.02$ & .345 \\
Anxiety & 0.07 & 0.05 & 2.12 & 1 & 1.07 & $0.98-1.17$ & .146 \\
PTSS & 0.30 & 0.37 & 0.66 & 1 & 1.35 & $0.65-2.81$ & .417 \\
Cancer worry & -0.01 & 0.06 & 0.01 & 1 & 0.99 & $0.89-1.12$ & .922 \\
Pain catastrophizing & 0.08 & 0.03 & 8.32 & 1 & 1.09 & $1.03-1.15$ & $\mathbf{. 0 0 4}$ \\
Age at diagnosis & 0.05 & 0.05 & 1.01 & 1 & 1.06 & $0.95-1.17$ & .314 \\
Depression & -0.06 & 0.05 & 1.62 & 1 & 0.94 & $0.86-1.03$ & .203 \\
\hline
\end{tabular}

Note: Nagelkerke pseudo $R^{2}=.297$. 